\title{
$\left.\mathbf{C}^{-}\right\rceil$CONGRESO
INTERNACIONAL \\ SOBRE \\ LF_O FOTOGRAFÍA
}

Congreso Internacional sobre Fotografía

UPV, 5 y 6 octubre 2017

Doi: http://dx.doi.org/10.4995/CIFo17.2017.6978

ISBN: 978-84-9048-604-7

\section{Render-punctum: El efecto de la imagen en el pensamiento y la gestión de la ciudad}

Inés García Clariana. Universidad Europea de Valencia, ines.garcia@universidadeuropea.es

\begin{abstract}
Synthetic images generate the desire of an architecture's existence through an image-render. This makes us reflect on the effect that the appearance in the mass media of an image-render could provoke with through time. The reappearance in image format of certain types of architectures, evokes the memory around the building, but also involves, in a certain way, all the urban management processes that have been taken over and happened in the city. We speak in short of all that past that a render (not even an existing reality) can provoke and bring back to our present. A punctum effect, as would define it Barthes, a certain movement of consciousness and past states that return through a visual effect to the present, through this render-punctum. This power that the image has in certain contexts to exercise itself as a tool of thinking, this trip to the past in the states of the city helps to rethink it to improve it.
\end{abstract}

Keywords: render, city, architecture, punctum, memory, management

\section{Resumen}

Las imágenes sintéticas generan el deseo de la existencia de una arquitectura a través de un render. Este hecho nos hace reflexionar sobre el efecto que la aparición una imagen-render en los medios de comunicación de masas pudiera provocar con el paso del tiempo. La reaparición en formato imagen de ciertas arquitecturas, evoca a la memoria en torno al edificio, pero también imputa en cierto modo a todos los procesos de gestión urbanística que se hayan tomado sobre él y acontecido en la ciudad. Hablamos en definitiva de todo aquel pasado que un render (ni siquiera una realidad existente) puede provocar y traer a nuestro presente. Un efecto punctum, que definiría Barthes, o lo que es lo mismo, un cierto movimiento de conciencias y de estados del pasado que vuelven a través de un efecto visual al presente, mediante este render-punctum. Este poder que tiene la imagen en ciertos contextos de ejercer en sí misma como herramienta de pensamiento, este viaje al pasado en los estados de la ciudad ayuda a repensarla para mejorarla.

Palabras clave: render, ciudad, arquitectura, punctum, memoria, gestión 


\section{Introducción}

Los motores que activan esta investigación - la fotografía y la arquitectura- han mantenido en el tiempo una relación de necesidad mutua tintada de deseos por extraer y plasmar la realidad. El diseño de artilugios y dispositivos para captar la arquitectura ha constituido un leitmotiv en el avance de la técnica fotográfica, y la presencia y existencia de la arquitectura ha promovido esfuerzos y motivaciones por llegar a representarla, a lo que se suma, que gracias a la fotografía el registro de la arquitectura en la retina de los arquitectos ha potenciado y transformado su imaginación.

En algo menos de dos siglos de historia de la fotografía - desde la Ventana de Le Gras de Joseph Nicéphore Niépce en 1826- la evolución de la técnica fotográfica ha dado un salto exponencial, y con ello el concepto de imagen, su comunicación, su difusión y su comprensión e interpretación. Del mismo modo la arquitectura ha ubicado su conducta de representación en otro estatus tecnológico, afectando esto a su asimilación formal y descernimiento espacial. Ambas disciplinas -ya ubicadas hoy día en el mundo de lo digital- están cercadas de nuevos conceptos: extensiones jpg, formatos raw, píxeles, infografías, renders, etc.

Como consecuencia de estos avances nos ha acontecido el exceso de representación de las cosas. La abundancia de la imagen y la superproducción se han implantado sin previo aviso. Hoy por hoy encontramos (queramos o no) múltiples representaciones visuales de una misma arquitectura provenientes de fuentes y medios muy diversos, más o menos especializados, y más o menos próximos a la realidad representada. Todo esto ha ido propagando la construcción de imaginarios dispersos frente a la arquitectura representada, a lo que se suma una cuestión superior llegándose a polemizar la propia existencia de lo representado. Nos encontramos en un estado en el que lo real desaparece y la representación se hace presencia -realidad-.

En estos términos la fabricación de imágenes sintéticas, infografías y renders a través de software de diseño avanzado que perfeccionan de manera acelerada el efecto de hiperrealidad, ha provocado un importante impacto de consumo y cambios de comportamiento hacia la imagen de arquitectura incidiendo de manera relevante en el imaginario sobre ella. Las imágenes render de arquitectura (in)existente despiertan sentimientos y reflexiones en torno al objeto representado, avivando el estado de la cuestión de la arquitectura y la ciudad en el presente. El render ejerce un efecto caja de pandora, provocando lo que en términos barthesianos catalogaríamos de punctum, de movilizador de conciencias sobre la gestión y los procesos de ciudad. En este artículo atenderemos desde un enfoque en positivo al aporte que genera la imagen sintética en el pensamiento de la arquitectura y la ciudad, y cómo la producción de renders abre canales que cuestionan los modos de actuación en ella. 


\section{Objetivos}

\subsection{Sobre la imagen sintética. ¿Qué es un render?}

Resulta necesario -aunque sea algo básico y evidente- empezar definiendo qué es un render. Consideremos al render tanto como una imagen digital de síntesis, como al propio proceso de su generación (renderización) creado a partir de un modelo o escenario en tres dimensiones producidos por software de diseño 3D. Por lo tanto, con esta definición de partida y extrapolando a nuestro planteamiento, estamos hablando de representaciones de arquitectura y ciudad en el que un alto porcentaje de los casos -como hemos comentado en la introducción del artículo- no existen en el mundo real, y que muchos de ellos son generados con el deseo de existir o incluso, para soñar.

Estas imágenes entran en la dimensión de la simulación, son simulacros (Baudrillard, 1987) arquitectónicos que en ocasiones provocan el crimen perfecto (Baudrillard, 2000)de una realidad todavía no construida, siendo habitada y consumida, habiendo pasado con el tiempo a ejercer de la «venta sobre plano» a la «venta sobre render». Para llegar a entender el efecto que provoca actualmente el render en el pensamiento de la ciudad, se hace necesario plantearnos previamente qué aportaciones ha ejercido (y ejerce) la imagen fotográfica en torno a la arquitectura y la ciudad en el hiostórico y evolución de ambas.

\subsection{Consideraciones sobre la fotografía, la imagen y el render}

La fotografía se ha consolidado dentro del campo tectónico como herramienta de supervivencia y vida de las ciudades más allá de su escala 1:1, como demuestra la fotografía de William Henry Fox Talbot de Trafalgar Square de 1844 y su actualización visual a través de Google Street View. La arquitectura y la ciudad, con el tiempo, se han dejado seducir por todo tipo de software, aplicaciones y plataformas para ser transformadas, transportadas y observadas desde múltiples puntos de vista hasta entrar en una especie de pérdida del sentido del espacio construido, y una multiplicidad de subjetividades diversas en torno a las ciudades, generando imaginarios diversos y dispersos sobre la imagen de una misma ciudad.

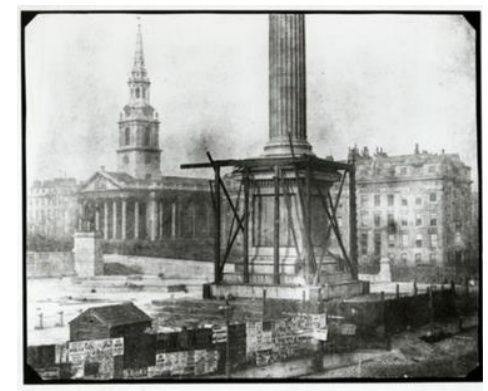

Fig. 1 William Henry Fox Talbot. Trafalgar Square. 1844

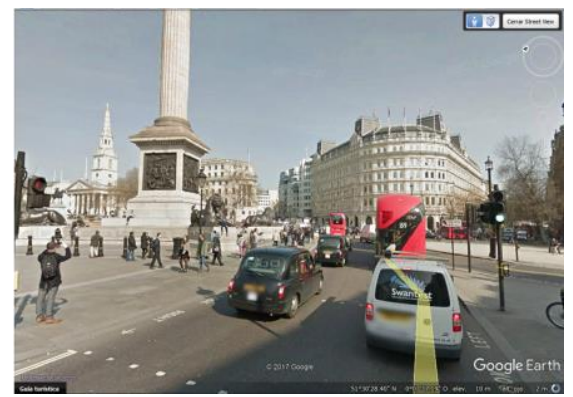

Fig. 2 Google Street View. Trafalgar Square. 2017.

Desde la aparición de la herramienta fotográfica las imágenes han servido de fuente de observación sobre los nuevos modos de vida, el espacio, la ciudad y la arquitectura, además de ejercer de mecanismo activador en la producción arquitectónica. La fotografía ha colaborado en la confección de inventarios visuales y ha actuado 
Render-punctum: El efecto de la imagen en el pensamiento y la gestión de la ciudad

como instrumento documental, dotando a la arquitectura y la ciudad de eternidad aparente. Gracias a la fotografía y a su poder documental mantenemos viva la historia de nuestras ciudades estimulando nuevos avances y gestiones sobre ellas.

Ahora bien, este alto potencial que dota a la imagen de poder de cambio e influencia sobre la imagen de la ciudad, no siempre ha sido recibido positivamente. La imagen sigue siendo actualmente controvertida. Si remontamos tiempo atrás vemos cómo la fotografía desde su invención fue cuestionada (y temida). En sus inicios la herramienta fotográfica fue considerada una amenaza para ciertas prácticas artísticas que percibieron a la fotografía como intrusa en el campo de las artes, anulando el valor del proceso creativo y en definitiva, de lo considerado único y auténtico. Testimonio conocido de ello son las palabras enunciadas por Baudelaire en $E l$ público moderno y la fotografía en 1859, unas declaraciones dirigidas en contra de lo vulgar -que según Baudelaire- tenía la fotografía. Más que emprender una campaña anti-fotográfica el autor asoció la fotografía con la pereza, la democracia, la industria, la obscenidad y la memoria, además de alertar sobre la anulación de la individualidad y el esfuerzo (Calvo, 2006).

Esta polémica inicial en torno a la herramienta fotográfica ha acompañado a la imagen hasta nuestros días. Irónicamente uno de los grandes debates abiertos en torno a la fotografía y la imagen hoy día, contradice a la función principal de su origen: la fotografía fue considerada como herramienta de reproducción fiel a la realidad, y hoy por hoy, es cuestionada en cuanto a lo real y verdadero que hay en ella. La cuestión de la veracidad de la imagen queda en ocasiones en entredicho ante los múltiples mecanismos con los que contamos para manipular el objeto fotográfico y la imagen, así como el gran número de teorías y estudios que rodean al mundo de lo visual en torno a este tema. No cabe duda de que la imagen se ha hecho escurridiza y el paso del tiempo y su trayectoria la han cercado en la desconfiada. La expresión y (re)presentación visual está rodeada de dudas y polémica.

En este estado de uso, de producción masiva de la imagen y escepticismo sobre ella, son muchos los autores alentados a reflexionar sobre su impacto, sobre su mensaje, no cesando de introducir conceptos y vocablos en un intento perseverante de someter a la imagen bajo control; la ecología de la imagen (Sontag, 2010) , la posfotografía (Fontcuberta, 2016), la factografía, la reflectografía, etc., todos conceptos teóricos que ponen a la imagen en el punto de mira y reflexión. Tal y como afirma Virilio (1998) sobre la velocidad de la historia -a la que contribuye enormemente la estética visual con sus pros y sus contras- o como se cuestiona Baudrillard (1987) sobre la simulación operativa de las cosas y su representación, a veces el mundo de la imagen es más intenso que el mundo real y ya no sólo se cuestiona la veracidad de la información, sino la existencia de la misma.

En este contexto, la imagen render se ha convertido en un instrumento de duda ante la realidad, pero también en una herramienta de adelanto de la misma. La arquitectura que será, es posible conocerla a través del render. El render es capaz de aventajarse a los tiempos, de movilizar los mercados, de promover la venta de arquitecturas todavía no construidas y de generar deseos de ciudad en los ciudadanos, pero al mismo tiempo, el reder activa 
la memoria de esas arquitecturas, de sus trayectoria en el tiempo, de las decisiones y gestiones en torno a ella, por lo que adquiere la capacidad de agitar la memoria de una ciudad: el render-punctum.

\subsection{Interés por la ciudad y la imagen}

El filósofo Francisco Jarauta en el 2008 en los seminarios sobre ciudad y su gestión organizados por Medialab Prado en Madrid formuló la sieguiente pregunta: ¿Y a quién no le interesa la ciudad hoy día?, o más bien, ¿quién no habla de ciudad? Esto podríamos extrapolarlo perfectamente a la imagen: ¿Y a quién no le interesa la imagen hoy día? ¿Quién no habla de imagen? ¿Quién no habla en imágenes? La arquitectura y la ciudad entendidas como mecanismos de complejidades múltiples- interesan a todos: a sociólogos, antropólogos y etnólogos, a filósofos, a políticos, al ciudadano, a la producción visual, a la fotografía y la imagen. Existen en la actualidad múltiples investigaciones y producciones en torno a la fotografía y la imagen de la arquitectura y la ciudad, tanto de artistas como de profesionales, teóricos y pensadores, en cuyos trabajos la fotografía es el medio de reflexión y producción.

Con ello se despierta que uno de los vínculos básicos entre la arquitectura y la ciudad, la fotografía y la imagen, es que se nutren y se (re)construyen mutuamente y permanentemente. La fotografía y la imagen ejercen -y me atrevería a decir que cada vez más- de herramienta de planificación y gestión de la ciudad desde la reflexión de la mirada. A lo que se suma el valor testimonial de la imagen sobre la ciudad y la arquitectura que ha sido (porque ya no existe), y la que será y existen tan sólo en imagen-render.

\section{Caso de estudio: Palacio de congresos de Valencia}

\subsection{Imágenes de gestión y planificación. Valencia}

Como cualquier ciudad Valencia cuenta con fotografías e imágenes que hacen las veces de ojo sociológico, arquitectónico y urbanístico. Fotografías que hablan de modos de vida y de comportamientos $-\mathrm{y}$ también de gestión- convirtiéndose en memoria RAM de la propia ciudad, una memoria práctica con la que pensar el presente. Fotografías que desvelan el porqué de ciertas decisiones urbanísticas motivadas en ocasiones por la propia supervivencia de la ciudad.

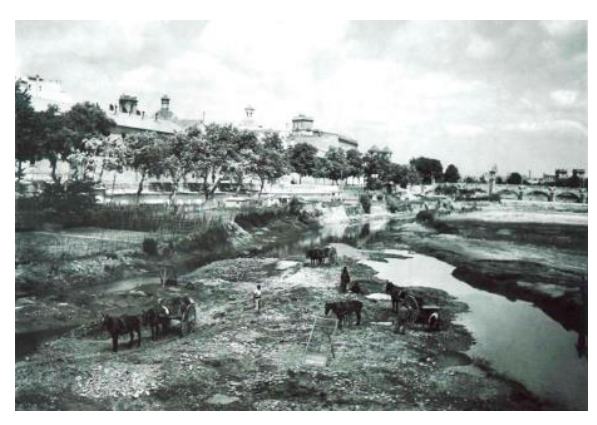

Fig. 3 Río Turia, año 1950

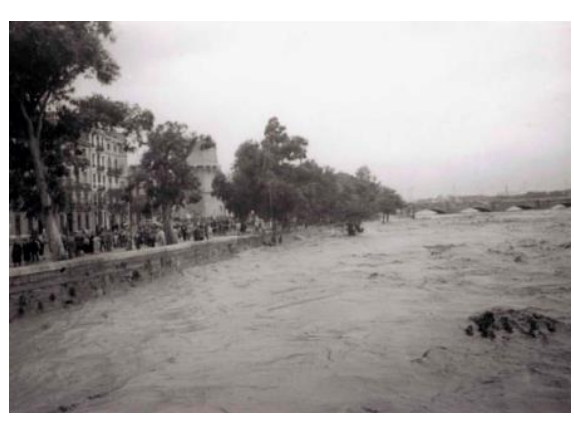

Fig. 4 Río Turia, riada del año 1957 
Pero también el pensamiento propositivo sobre la ciudad trae consigo imágenes fallidas sobre la misma, como muestra la propuesta de red de carreteras y vías rápidas embebidas en el antiguo cauce del río Turia (la consideramos en este caso imagen fallida por el acierto de no haber sido ejecutada). Las imágenes de fotomontaje proponen sueños y ciudades imaginadas, como la del ingeniero Luis Merlo del tren vertebrado aéreo en 1975 o la figuración propuesta por Tecpay en 1977 de diversos usos deportivos sobre el antiguo cauce del río Turia, constituyendo en sí mismas imágenes de la posibilidad, de ciudad.

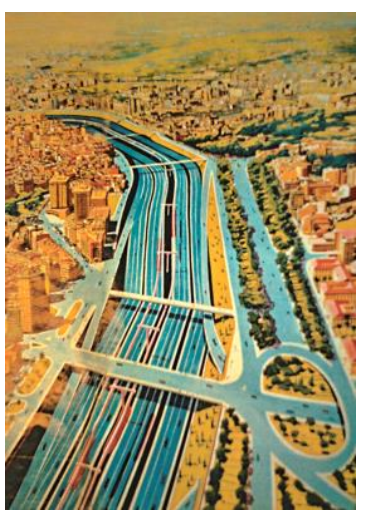

Fig. 5 Propuesta de uso del río Turia

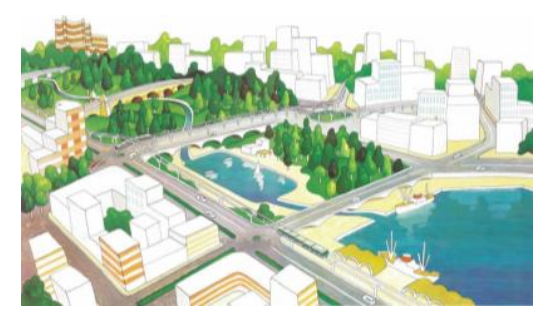

Fig. 6 Propuesta de Luis Merlo, 1975
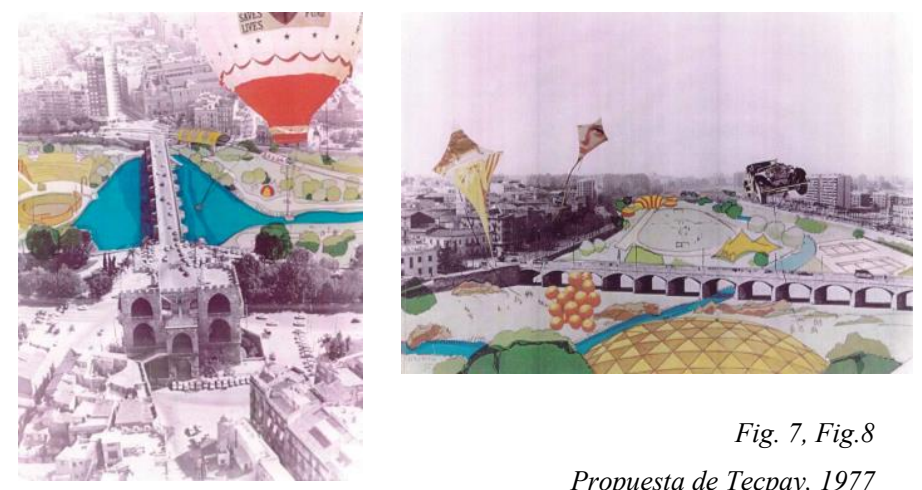

Fig. 7, Fig.8

Propuesta de Tecpay, 1977

Esta breve narrativa visual es un intento de mostrar cómo la imagen ejerce en el pensamiento de la ciudad y sus políticas de gestión y vida. Se suma a ello la imagen digital sintética, la infografía y el render, y reformulamos la cuestión abierta: ¿Qué efectos están produciendo estas imágenes digitales en torno a la arquitectura y la ciudad? Para trabajar sobre ello emplearemos como objeto de estudio el edificio del Palacio de Congresos de Valencia del arquitecto Norman Foster 


\subsection{La imagen del palacio y el arquitecto}

Imaginemos las múltiples realidades visuales que podrían producirse en torno a una arquitectura, incluyendo la imagen postal que nos ofrece el buscador Google. El edificio del Palacio de Congresos de Valencia del arquitecto Norman Foster cuenta con una gran producción en cuanto a fotografía e imagen se refire. En la fase de gestación de proyecto -entre 1993 y 1995- Foster emplea como medio de representación el dibujo, la maqueta y la fotografía de maqueta, que se convierten en herramientas clave para la exteriorización de la imagen de un edificio todavía por existir. Cabe señalar que en esta época -y dado los todavía parcos avances en la representación digital de la arquitectura- la fotografía de maqueta tenía más peso de expresión que el render de la época.

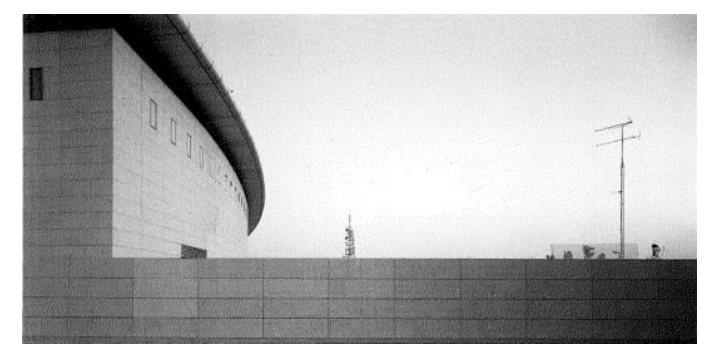

Fig. 9 Palacio de Congresos de Valencia. Manolo Laguillo. 1998

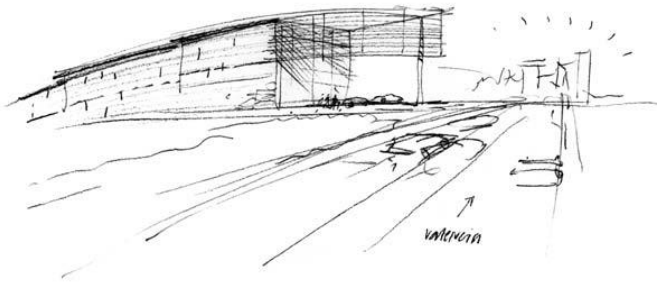

Fig. 11 Palacio de Congresos de Valencia. Boceto de Norman Foster. 1994

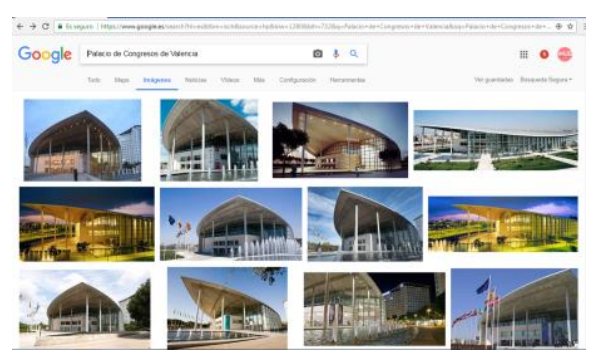

Fig. 10 Palacio de Congresos de Valencia. Google. 2017

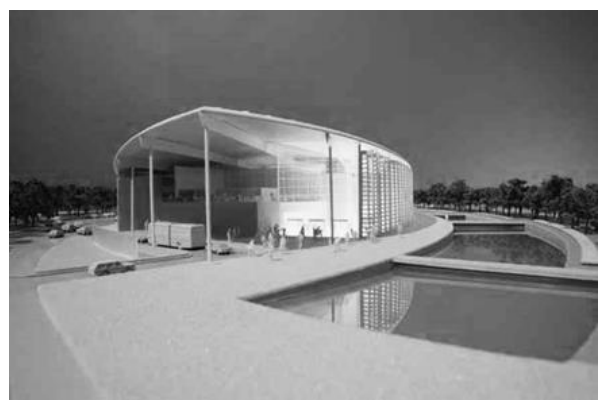

Fig. 12 Palacio de Congresos de Valencia. Fotografia de maqueta de Nigel Young. 1994

A todo ello se suma a través de la imagen mediática la fotografía de prensa. Será el periódico Levante el Mercantil Valenciano quien obrará la figura mesiánica del arquitecto Norman Foster en la ciudad de Valencia, colaborando a través de sus titulares, noticias y fotografías en forjar un imaginario mediante la construcción de un personaje mediático (Norma Foster), que legitimará y aportará un supuesto sello de calidad a la arquitectura del Palacio de Congresos de Valencia. Del orden de unas 40 noticias de las 73 registradas en el periódico el Levante referidas a Foster y su Palacio de Congresos - desde su visita a Valencia en 1992 hasta la inauguración en 1998- configuran el montaje en torno al arquitecto, que no hace más que legitimar un encargo efectuado a dedo por los poderes de gestión política de la ciudad, hasta generar toda una Fosterfascinación mediática en torno al arquitecto. 

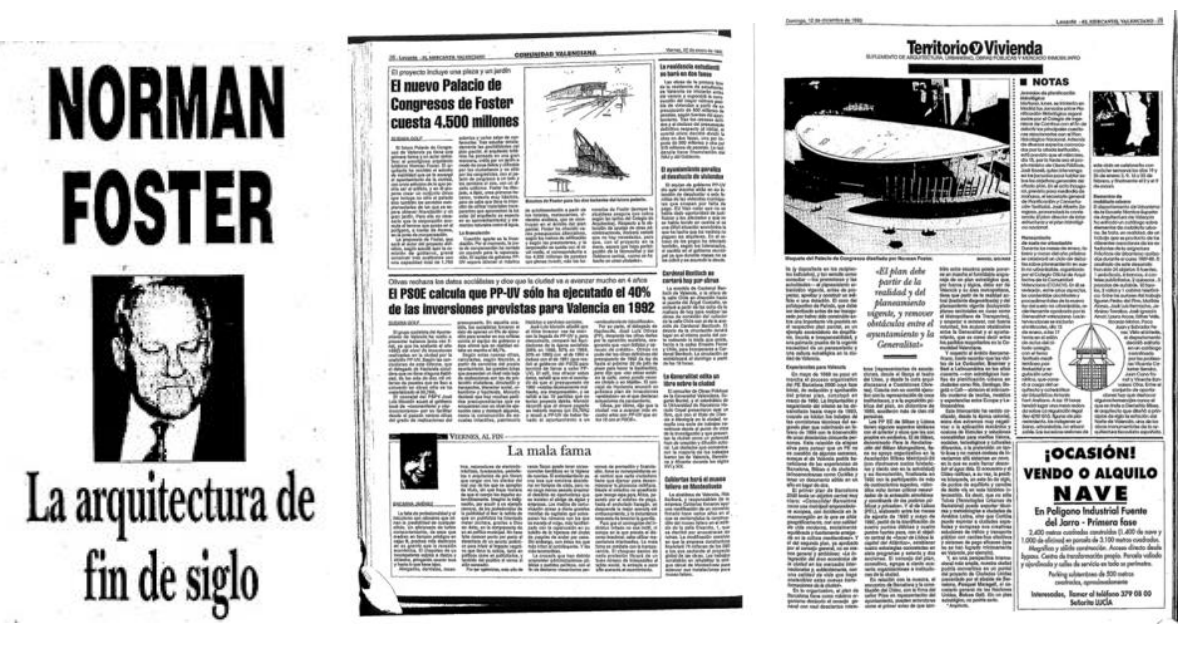

Fig. 13 Suplemento Territorio y Vivienda. Levante. 1995

También la revista especializada de arquitectura documenta y fotografía este edificio de Norman Foster, connotando en algunos casos a la imagen bajo un mensaje sensacionalista, como es el caso del artículo recogido en el $n^{\circ} 34$ de la revista AV publicada en agosto de 1994, que recoge estas palabras de la arquitecta valenciana Cristina Grau:

\begin{abstract}
La popular — en todos los sentidos - alcaldesa de la ciudad, Rita Barberá, ha demostrado saber no sólo de economía doméstica, sino también de economía urbana y, además, de cocina de cinco estrellas. Sabe que hay que tener una buena receta, unos buenos ingredientes elegidos personalmente - la cocina de mercado, y no concursos donde no se sabe qué saldrá al final—y un buen chef. El resultado tiene que ser bueno. Su elección personal del arquitecto — que nunca ha estado en el vaivén de las modas y que por tanto hará un edificio que no se pasará de moda - promete un recuerdo estable en el paladar.
\end{abstract}

Todo este archivo visual construye la memoria - en imágenes- de la ciudad de Valencia en uan minúscula parte, en torno al Palacio de Congresos, e incide en la construcción del imaginario colectivo de la misma.
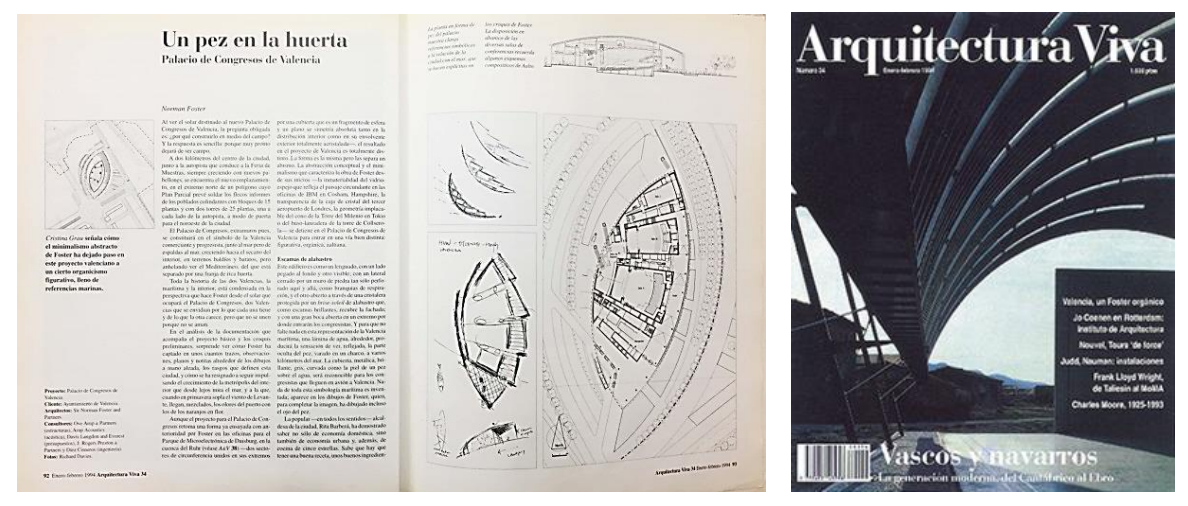

Fig. 14 Revista $A V n^{\circ} 34$. Artículo de Cristina Grau 
La imagen del propio arquitecto es algo que también se vincula al producto imaginativo de su arquitectura: por un lado vemos cómo él mismo, desde la máquina interna que es la firma Foster\&Partners aparece como cabeza visible en: películas, documentales, revistas, programas televisivos, etc. Y por si fuera poco en su reciente cuenta de instagram podemos verlo en actitudes domésticas y desenfadadas, saber lo que come Foster y lo que le gusta. Con una media de 5000 me gustas/foto se constata que es una figura mediática y que como tal, su imagen como personaje connota al imaginario de su arquitectura.
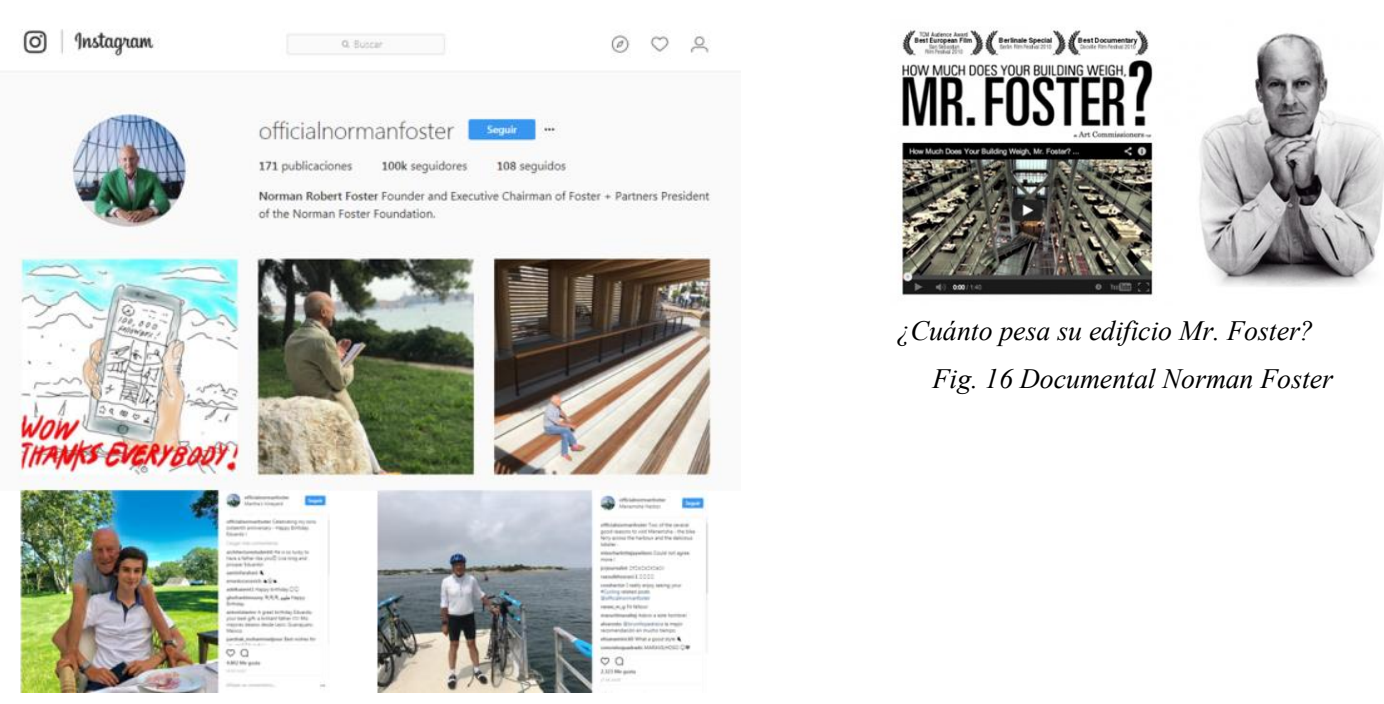

Fig. 16 Documental Norman Foster

Fig. 15 Instagram Norman Foster

\subsection{El render del Palacio de Congresos}

Dando un salto en el tiempo, al 30 de noviembre de 2011, trece años después de la inauguración del Palacio de Congresos de Valencia, aparece publicada en el periódico El Mundo (versión digital) la noticia de ampliación del Palacio de Congresos: «Así será el nuevo Palacio de Congresos de Valencia» diseñado por Norman Foster. Poco interés podría suscitarnos la noticia si no rescatamos las imágenes de archivo en torno al Palacio de Congresos de Valencia; desde 1992 — fecha por el que establece el encargo 'a dedo' que la alcaldesa Rita Barberá firmó con Sir Norman Foster- hasta 1998 (seis años más tarde) cuando aparece un amplio reportaje de la inauguración del edificio realizado por reportero gráfico José Aleixandre del periódico Levante bajo el titular: «El Rey ve en el palacio de Foster un símbolo de la nueva Valencia». Esta trayectoria en la historia del edificio y la posterior gestión del mismo influirá inevitablemente sobre la recepción del render en el 2011.

Un escaso texto y un par de imágenes sintéticas ilustran la noticia, no hay maqueta, ni fotografía de maqueta, y se suma el render un vídeo en el que el propio arquitecto Norman Foster anuncia la ampliación del Palacio de Congresos. 


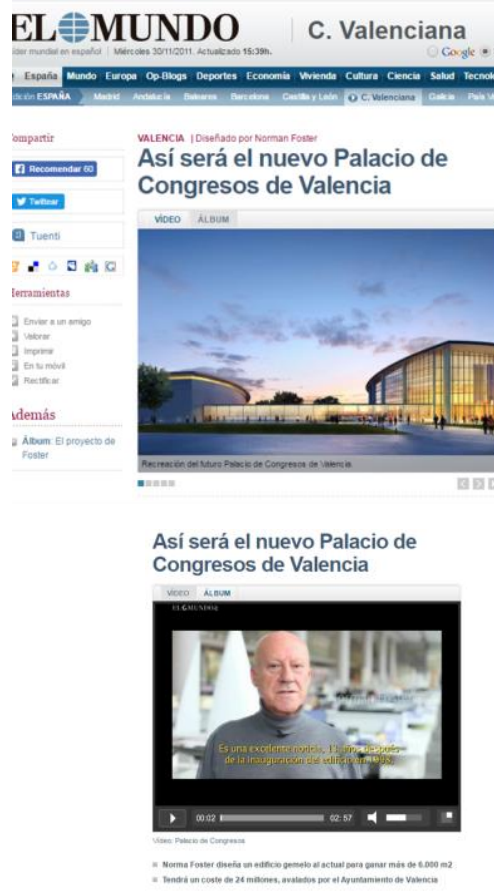

Fig. 17 Imágenes render de la noticia en periódico El Mundo

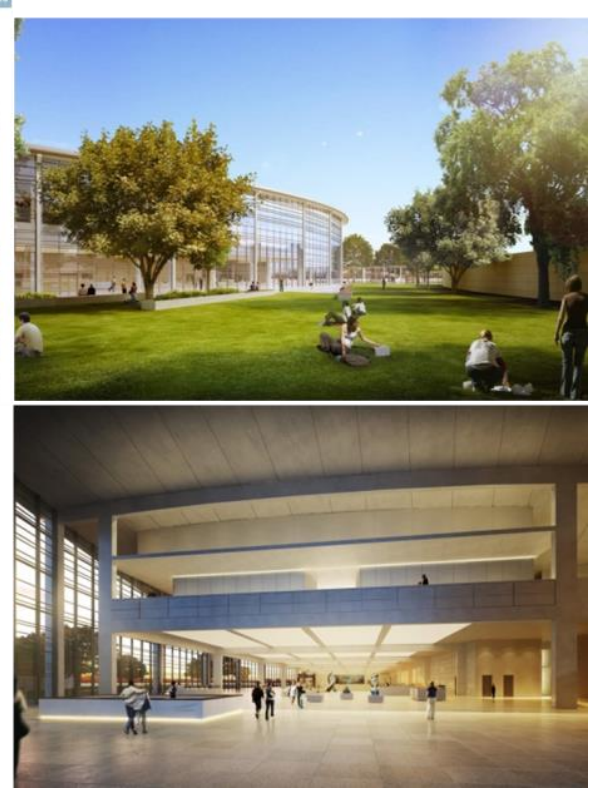

Fig. 18 Video de Norman Foster anunciando ampliaciaón del Palacio de Congresos

La futura ampliación del Palacio de Congresos de Valencia nunca llegó a ejecutarse. Ahora bien, la noticia en torno a la ampliación del Palacio de Congresos y la imagen sintética quedaron (hoy por hoy) en el deseo que marcó su existencia a través de una imagen (render), dentro de un contexto de gestión urbanística en el que la ciudad de Valencia adolecía por muchos frentes. Este hecho nos hace pensar sobre el posible efecto que la aparición de esta imagen-render puede provocar en el presente poniendo sobre la mesa gestiones del pasado. Esta reaparición en formato imagen evoca a la memoria del edificio, pero también imputa en cierto modo a todos los procesos de gestión urbanística que desde los años '90 hasta la fecha han acontecido en la ciudad. Hablamos en definitiva de todo aquel pasado que un render (ni siquiera una realidad existente) puede provocar y traer a nuestro presente.

Esta idea de Ramtrip, un viaje por la memoria RAM de la que habla Miguel Ángel Hernández Navarro, desplazamientos para pensar el presente a través de la revisión de nuestro pasado, posee ese efecto que señala Barthes de punctum (1989), o lo que es lo mismo, un cierto movimiento de conciencias y de estados del pasado que vuelven a través de un efecto visual al presente, mediante este render-punctum del Palacio de Congresos. Este poder que tiene la imagen en ciertos contextos, de ejercer en sí misma como herramienta de pensamiento, este viaje al pasado en los estados de la ciudad, ayuda a repensarla para mejorarla. De hecho, estos estados de la cuestión, escenas sobre las que pensar -ejercen en la sociología visual- crean un observatorio urbano improvisado, desde ese mirar prestando atención que tanto demandó Berger. 
Esta reflexión abierta sobre la ciudad, sobre los modelos de gestión política y urbanística a través de la imagen, despiertan también consecuencias visuales, como la que se recoge en la publicación La Huerta de Valencia: evolución, influencia del planeamiento urbanistico y perspectivas de Víctor Soriano, en la que se muestra cómo el área de Ademúz en el que se inserta el Palacio de Congresos estaba computada dentro de las 15.000 hectáreas de huerta que en los últimos 50 años ha perdido la ciudad de Valencia. Hecho éste que las fotografías de Bernard Plossu y Manolo Laguillo de 1998 ya anunciaban a modo de alerta sobre un paisaje en peligro de extinción, y que hoy día queda constatado.

Fig. 19 Pista de Ademúz, 1998

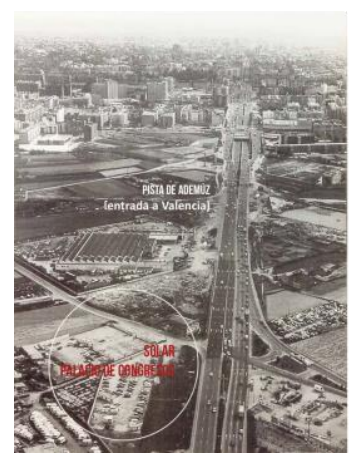

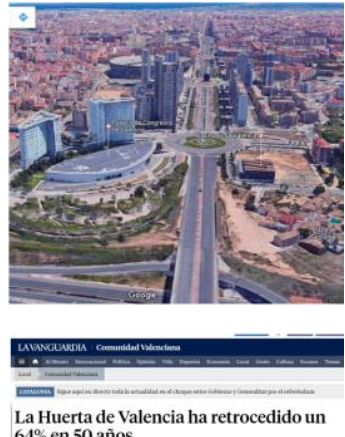

64\%en 50 años
Fig. 20 Pista de Ademúz, Google, 2017

Fig. 21 Noticia periódico La Vanguardia, 2015

Las escenas fijas que aportan la fotografía, el render y la fotografía de maqueta tienen el poder de remover conciencias poniendo el pasado a pulso y el presente en cuestión, generando un observatorio urbano improvisado y abriendo reflexiones en torno a la ciudad y su gestión. Esta imagen imputada -render- casi 20 años más tarde de la inauguración del Palacio de Congresos, despierta el resto de archivo de imágenes de la ciudad, ejerciendo de examen de conciencia de una gestión urbanística que intenta hoy día cicatrizar.

\section{Conclusiones}

Son muchas las imágenes en la actualidad que generan nostalgia hacia una Valencia que podría haber sido, y no por el deseo de la arquitectura y de la construcción que muestra el render, sino por poner sobre la mesa la importancia de generar un ojo sociológico (Bourdier) urbano que incida directamente sobre las necesidades reales de la ciudad y los ciudadanos. El caso del Palacio de Congresos es tan sólo un ejemplo que se suma a la imagen-falla de la Torre de Comunicaciones no construida de Santiago Calatrava, a la imagen escala 1:1 de la arquitectura del Centro de Investigación Príncipe Felipe — cerrado, y sin presupuesto para la investigación, a la vista aérea de Google Earth que muestra las 170 crestas de hierro del Ágora de Santiago Calatrava posadas y abandonadas, hasta los renders de los rascacielos de acceso a la ciudad. Todas estas imágenes desembocan hoy día en una realidad castrada, de gestiones a medias, de proyectos por terminar, que además, se extienden como metástasis urbanas actuando como señales de un pasado. El render, la imagen, remueve y enciende cuestiones en la gestión de la ciudad despertando nuevamente el archivo de imágenes de nuestro imaginario. 


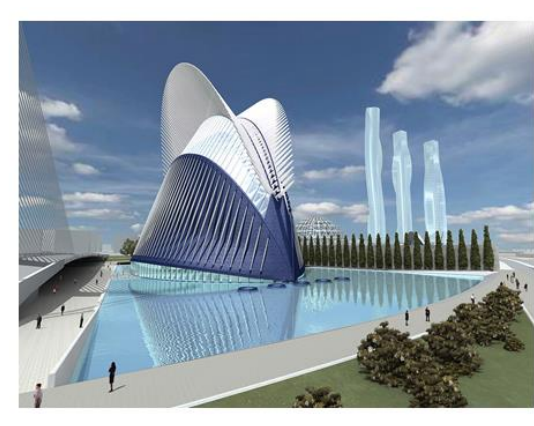

Fig. 21 Render del Ágora de Santiago Calatrava. Ciudad de las Ciencias

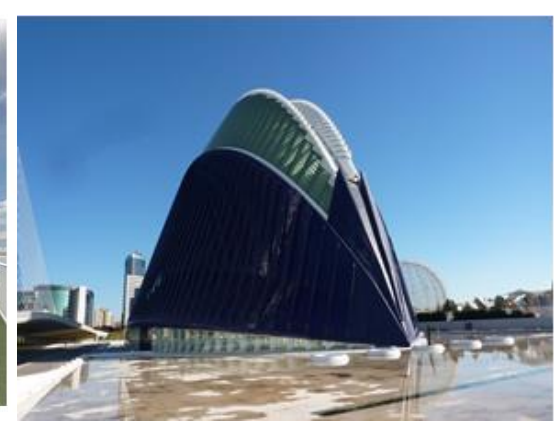

Fig. 22 Fotografia del estado del Ágora de Santiago Calatrava. Ciudad de las Ciencias

\section{Referencias}

BARTHES, Roland (1989), La cámara lúcida. Barcelona, Paidós.

BAUDRILLARD, Jean (2000), El crimen perfecto. Barcelona, Anagrama.

BAUDRILLARD, Jean (1987), Cultura y simulacro. Barcelona, kairós.

BOURDIEU, Pierre, La fotografía como arte intermedio, versión electrónica a cargo de Óscar I. Martínez Gómez de la Universidad Nacional Autónoma de México, Facultad de Ciencias Políticas y Sociales (http://es.scribd.com/doc/7286264/Pierre-Bourdieu-La-Fotografia)

CALVO SERRALLER, Francisco (2006), 'La producción y reproducción mecánica de la imagen'. El Arte Contemporáneo. Madrid, Taurus-Santillana.

FONTCUBERTA, Joan (2016). La furia de las imágenes. Notas sobre la postfotografía. Barcelona, Galaxia Gutenberg.

LYNCH, Kevin, The image of the city (Harvard-MIT Joint Center for Urban Studies Series)

PALLASMAA, Juhani, (2014), La imagen corpórea. Imaginación e imaginario en la arquitectura. Barcelona, Gustavo Gili SONTAG, Susan (2010), Sobre la Fotografia. Barcelona, Liberdúplex.

VIRILIO, Paul, (1998), La máquina de visión. Madrid, Ediciones Cátedra S.A. 